Research Article

\title{
Prescription pattern in indoor patients of cardiovascular diseases: a descriptive study in a tertiary care hospital attached to a government medical college
}

\author{
Pravin S. Rathod ${ }^{1}$, Praveenkumar T. Patil $^{1}$, Rekha P. Lohar ${ }^{2}$, A. W. Patil ${ }^{1}$
}

\begin{abstract}
${ }^{1}$ Department of Pharmacology, SBH GMC, Dhule, Maharashtra, India,

${ }^{2}$ Department of Community Medicine, SBH GMC, Dhule, Maharashtra, India

Received: 02 February 2016 Accepted: 02 March 2016

\section{*Correspondence to: \\ Dr. Pravin S. Rathod, \\ Email: drpslohar@ \\ rediffmail.com}

Copyright: (C) the author(s), publisher and licensee Medip Academy. This is an openaccess article distributed under the terms of the Creative Commons Attribution NonCommercial License, which permits unrestricted noncommercial use, distribution, and reproduction in any medium, provided the original work is properly cited.
\end{abstract}

\begin{abstract}
Background: In India, one of the leading causes of death is cardiovascular diseases (CVDs). The study of prescription pattern ensures rational pharmacotherapy and assures quality medical care to the patients. Hence the present study was conducted to observe the prescription pattern of drugs among the indoor patients of cardiovascular diseases in a tertiary care hospital attached to a Government Medical college.

Methods: A retrospective observational study of 9 month duration was undertaken from January- September 2015. A total number of 113 indoor cardiovascular disease patients' case sheets were utilized for our study from medicine and ICCU department of a tertiary care hospital. The data was analysed and the results were expressed as counts and percentage.

Results: Of 113 patients, most of the patients were of the age group of 56-65 years $(40.71 \%)$. The prevalence of CVDs was higher in females $(56.64 \%)$ than males $(43.36 \%)$. Hypertension $(58.41 \%)$ and Ischemic heart disease $(41.59 \%)$ were found to be predominant CVDs. Nifedipine (53.10\%), Atenolol (31.86\%), Isosorbide dinitrate $(40.71 \%)$, Atorvastatin $(53.10 \%)$ were the most commonly prescribed cardiovascular drugs. Aspirin and Clopidogrel combination was prescribed in $46.90 \%$ of CVD patients. The average number of drugs per prescription was 6.53 .

Conclusions: The present study shows that most of drugs were prescribed rationally according to the current treatment guidelines except the under use of ACEIs and ARBs in hypertensive diabetes mellitus patients. Standard treatment guidelines should be circulated among practicing physicians to encourage rational prescription.
\end{abstract}

Keywords: Cardiovascular diseases, Prescription Pattern, Indoor patients, Hypertension, Ischemic heart disease

\section{INTRODUCTION}

Cardiovascular diseases (CVDs) are major health problem throughout the world and common cause of premature morbidity and mortality. ${ }^{1}$ Today CVD accounts for approximately $30 \%$ deaths worldwide including nearly $40 \%$ in high income countries and about $28 \%$ in middle and low income countries. The global rise in CVD is the result of industrialization, urbanization and associated life style changes. $^{2}$

CVDs generally affect the heart and the circulatory system which includes hypertension, Ischemic heart disease (IHD), congestive heart failure (CHF), stroke, peripheral artery disease and rheumatic heart disease. Important modifiable risk factors of CVDs are unhealthy diet, physical inactivity, tobacco use and the effects insinuate abnormal blood lipid profile and obesity. ${ }^{1}$

Various classes of drugs are available for the management of CVDs. Commonly used drugs to treat CVDs are vasodilators, calcium channel blockers, beta blockers, diuretics, angiotensin converting enzyme inhibitors, angiotensin receptor blockers, antiplatelet and lipid-lowering agents. The most important factor in the treatment of either subclinical or clinical CVD is the presence of co-morbidities. ${ }^{3}$ 
Rational drug prescribing is defined as the use of the least number of drugs to obtain the best possible effect in the shortest period and at a reasonable cost. ${ }^{4}$

The study of prescribing pattern is a component of medical audit that does monitoring and evaluation of the prescribers as well as recommends necessary modifications to achieve rational and cost-effective medical care. ${ }^{5}$ Irrational prescribing of drugs is of common occurrence in clinical practice, important reasons being lack of knowledge about drugs, unethical drug promotions and irrational prescribing habits of clinicians. Inappropriate prescribing habits lead to ineffective and unsafe treatment, prolongation of illness, distress and unnecessary economic burden to the patient. ${ }^{6,7}$ Erroneous prescriptions are recognized even in the tertiary care hospital. ${ }^{8}$

There are very few studies on indoor cardiovascular disease patients under government hospital settings. Therefore, the present study attempts to analyse the current prescription patterns in indoor patients of cardiovascular diseases in a government tertiary care hospital in order to ensure appropriate drug use to reduce the morbidity and mortality of the disease.

\section{METHODS}

This was a retrospective observational study conducted in a tertiary care hospital attached to SBH Government Medical College, Dhule. The study duration was nine months from January 2015 to September 2015. A total of 113 Patients who were admitted under medicine department and ICCU with cardiovascular diseases were included in the study. Undiagnosed patients and those with incomplete case record sheets were excluded from the study. Source of data was collected from patient's case sheets obtained from Medical Record Section. Patient's details such as name, age, sex, complaints, diagnosis, treatment details were collected. The study was approved by Institutional Ethics Committee. The data was computed using MS Excel and descriptive results were expressed as counts and percentages.

\section{RESULTS}

Most of the patients diagnosed with cardiovascular diseases were of the age group of 56-65 years $(40.71 \%)$ followed by $66-75$ years $(21.24 \%$ ) age groups (Figure 1 ). Female population $(56.64 \%)$ had higher prevalence of cardiovascular diseases than males (43.36\%) (Figure 2).

Extensive diagnosis made by the physician's revealed different cardiovascular diseases prevailing among the patients. $58.41 \%$ patients were reported to have Hypertension whereas $41.59 \%$ patients were diagnosed with Ischemic heart disease. Other conditions were stroke (18.58), congestive cardiac failure (7.96\%) and myocardial infarction in $3.54 \%$ patients (Table 1 ).
Table 1: Pattern of medical conditions among the indoor cardiovascular disease patients.

\begin{tabular}{|lll|}
\hline CVD & n & \% \\
\hline Hypertension & 66 & 58.41 \\
\hline IHD & 47 & 41.59 \\
\hline Stroke/ CVA & 21 & 18.58 \\
\hline CCF & 9 & 7.96 \\
\hline MI & 4 & 3.54 \\
\hline
\end{tabular}

$\mathrm{n}=$ number of patients, $\%=$ percentage

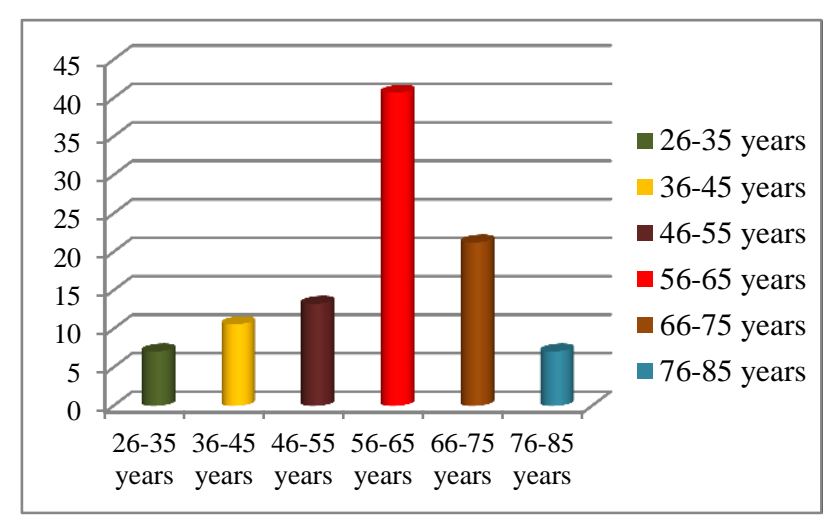

$\mathrm{n}=$ Number of patients

Figure 1: Age wise distribution of indoor cardiovascular disease patients $(n=113)$.

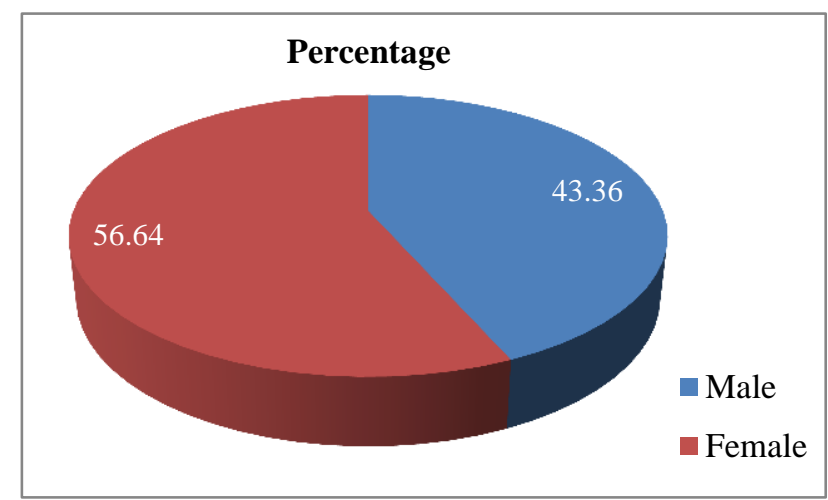

$\mathrm{n}=$ Number of patients

Figure 2: Gender wise distribution of indoor cardiovascular disease patients $(n=113)$.

Table 2: Comorbid conditions among the cardiovascular disease patients who needed hospitalization.

\begin{tabular}{|lll|}
\hline Comorbidity & n & \% \\
\hline HTN + IHD & 26 & 23.01 \\
\hline HTN + DM & 14 & 12.39 \\
\hline Kidney disease & 6 & 5.31 \\
\hline Arrhythmias & 5 & 4.42 \\
\hline Respiratory Disease & 5 & 4.42 \\
\hline Anaemia & 4 & 3.54 \\
\hline GIT disorder & 2 & 1.77 \\
\hline
\end{tabular}

$\mathrm{n}=$ number of patients; $\%=$ percentage 
Various co-morbid conditions like hypertension, diabetes mellitus, renal failure, Bronchial asthma, arrhythmias, and anaemia were seen among these patients. Hypertension $(23.01 \%)$ and diabetes mellitus (12.39\%) were the two most common co-morbid conditions found in most of the patients which increases the risk of cardiovascular disease morbidity and mortality (Table 2).

Table 3 shows the prescription pattern of various class of drugs for treatment of indoor cardiovascular disease patients namely antihypertensives, anti-anginals, Ionotropes, antiplatelet drugs, anticoagulants, hypolipidemic agents, Diuretics and thrombolytic agents. The usages of these drugs were recorded and analysed.

Table 3: Prescription pattern of drugs among indoor cardiovascular disease patients $(n=113)$.

\begin{tabular}{|lll|}
\hline Class of drug & $\begin{array}{l}\text { No of } \\
\text { prescriptions }\end{array}$ & $\begin{array}{l}\text { Prescription } \\
\text { rate }(\%)\end{array}$ \\
\hline Anti-hypertensive drugs & \\
\hline Nifedipine & 60 & 53.10 \\
\hline Atenolol & 36 & 31.86 \\
\hline Amlodipine & 11 & 9.73 \\
\hline Telmisartan & 5 & 4.42 \\
\hline Ramipril & 5 & 4.42 \\
\hline Metoprolol & 2 & 1.77 \\
\hline Losartan & 1 & 0.88 \\
\hline Antianginal Drugs & & \\
\hline Isosorbide dinitrate & 46 & 40.71 \\
\hline Nitroglycerine & 10 & 8.85 \\
\hline Nicorandil & 02 & 1.77 \\
\hline Hypolipidemic agents & & \\
\hline Atorvastatin & 60 & 53.10 \\
\hline Ionotropes & & \\
\hline Digoxin & 9 & 7.96 \\
\hline Dopamine & 2 & 1.77 \\
\hline Antiplatelets & & \\
\hline Aspirin & 43 & 38.05 \\
\hline Clopidogrel & 17 & 15.05 \\
\hline $\begin{array}{l}\text { Aspirin + } \\
\text { Clopidogrel }\end{array}$ & 53 & 46.90 \\
\hline Anticoagulants & & \\
\hline $\begin{array}{l}\text { Unfractionated } \\
\text { Heparin }\end{array}$ & 29 & \\
\hline Diuretics & 25.66 \\
\hline Furosemide & 5 & \\
\hline $\begin{array}{l}\text { Furosemide+Spironol } \\
\text { actone }\end{array}$ & 5 & \\
\hline Thrombolytic agents & & \\
\hline Streptokinase & & \\
\hline & & \\
\hline
\end{tabular}

Non cardiological drugs usage was also recorded and analysed (Table 4).
Table 4: Different categories of drugs prescribed for comorbid conditions among indoor cardiovascular diseases.

\begin{tabular}{|c|c|c|}
\hline Class of Drug & $\begin{array}{l}\text { No of } \\
\text { Prescriptions }\end{array}$ & $\begin{array}{l}\text { Prescription } \\
\text { rate }(\%)\end{array}$ \\
\hline \multicolumn{3}{|l|}{ Antidiabetic Drugs } \\
\hline Regular Insulin & 12 & 10.62 \\
\hline Metformin & 7 & 6.19 \\
\hline Glibenclamide & 4 & 3.54 \\
\hline Glimepiride & 2 & 1.77 \\
\hline \multicolumn{3}{|c|}{ Antimicrobial agents } \\
\hline $\begin{array}{l}\text { Amoxicillin+Clavul } \\
\text { anic acid }\end{array}$ & 30 & 26.55 \\
\hline Ceftriaxone & 14 & 12.39 \\
\hline Cefotaxime & 12 & 10.62 \\
\hline Ciprofloxacin & 10 & 8.85 \\
\hline Metronidazole & 4 & 3.54 \\
\hline \multicolumn{3}{|c|}{ Antiulcer/ antiemetic agents } \\
\hline Ranitidine & 77 & 68.14 \\
\hline Ondansetron & 14 & 12.39 \\
\hline Pantoprazole & 4 & 3.54 \\
\hline \multicolumn{3}{|l|}{ Bronchodilators } \\
\hline Theophylline & 24 & 21.24 \\
\hline Salbutamol & 4 & 3.54 \\
\hline Nebulization & 14 & 12.34 \\
\hline \multicolumn{3}{|l|}{ Anti-arrhythmics } \\
\hline Amiodarone & 3 & 2.65 \\
\hline Diltiazem & 2 & 1.77 \\
\hline \multicolumn{3}{|l|}{ Corticosteroids } \\
\hline Hydrocortisone & 10 & 8.85 \\
\hline Dexamethasone & 9 & 7.96 \\
\hline \multicolumn{3}{|l|}{ Anticonvulsants } \\
\hline Phenytoin & 12 & 10.62 \\
\hline Mannitol & 10 & 8.85 \\
\hline Multivitamins & 33 & 29.20 \\
\hline Cinnarizine & 3 & 2.65 \\
\hline
\end{tabular}

The most common route of administration of drugs was Oral $(57.10 \%)$ followed by intravenous route $(40.65 \%)$ (Figure 3).

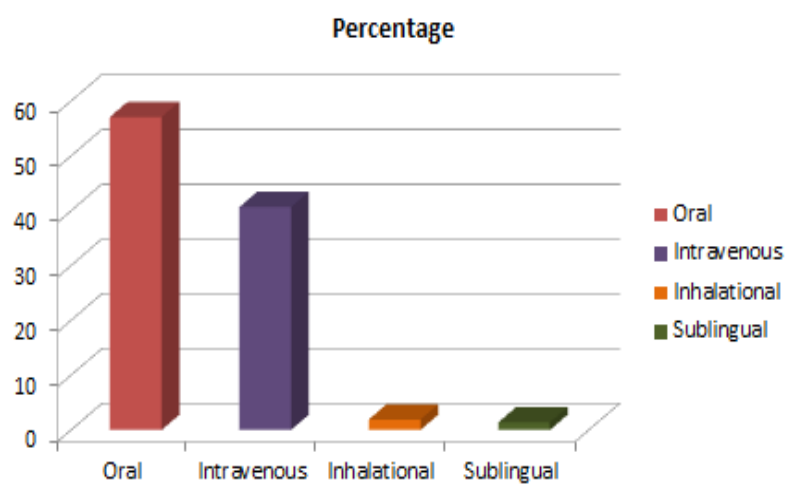

Figure 3: Frequency of route of administration of drugs among indoor cardiovascular disease patients. 
The average number of drugs per prescription was 6.53 (Table 5).

Table 5: Details of prescriptions of indoor cardiovascular disease patients expressed in numbers (percentage).

\begin{tabular}{|ll|}
\hline Details of prescriptions & Number \\
\hline Total no. of patient's prescriptions analysed & 113 \\
\hline Total number of drugs prescribed & 738 \\
\hline Average number of drugs per prescription & 6.53 \\
\hline
\end{tabular}

\section{DISCUSSION}

Considering the uncertainty of CVD patients and the various classes of drugs to be used in the treatment, the physician has to weigh the pros and cons of each and every drug before using it.

In the present study it was found that cardiovascular diseases were most common in the age group of 56-65 years $(40.71 \%)$ followed by $66-75$ years $(21.24 \%)$. These results are in concordance with the study by Patil SB, et al. They observed that a maximum number of patients, i.e., $39 \%$ were in the age group of 51-60 years, followed by $27 \%$ patients in the age group of $61-70$ years. This correlates with many studies which show increased the risk of CVD with increasing age. ${ }^{8}$

In the present study, prevalence of CVDs was higher in females $(56.64 \%)$ than males $(43.36 \%)$, which was variant from previous studies where males had higher prevalence than females. This may be explained as CVD risk factors become more prevalent in post menopause women as the mean age of women in the study was found to be $60 \pm 12.47$ years. $^{9}$ Inflammation, obesity, Type 2 DM and metabolic syndrome appear to play more prominent roles in the development of CVDs in women than men. ${ }^{10}$

In the present study, hypertension (58.41\%) and IHD $(41.59 \%)$ were the most common CVDs. Similar results were found in Zafar $\mathrm{F}$ et al study in which $31 \%$ patients had hypertension and $20 \%$ patients had IHD. ${ }^{11}$

Hypertension and diabetes were the two most common co-morbid conditions found in the present study which is in concordance with the previous studies by Nagabushan $\mathrm{H}$ et al and Christian RP et al. ${ }^{12,13}$ In addition to this HTN and DM both are risk factors to cardiovascular diseases. So apart from treating cardiovascular diseases patients may be educated about risk factors and life style modifications.

In the present study most commonly prescribed antihypertensive drugs were Calcium channel blockers (Nifedepine 53.10\%) and Beta blockers (Atenolol $31.86 \%$ ). As most of the CVD patients had DM as co morbid condition, ACEIs and ARBS are the most preferred drugs because of their cardio-protective and renoprotective effects. ${ }^{14}$ But in the present study both drugs were prescribed in few number of patients, reason could be lack of regular supply of these class of drug $s$ in the remote government tertiary care hospital.

In the present study, Isosorbide dinitrate $(40.71 \%)$ was the most commonly prescribed antianginal agent for prophylaxis and relief of ischemia among CVD patients.

In a study conducted by Tasneem Sandozi and Fouzia Nausheen the drug utilization of various antiplatelet drugs were as aspirin alone, aspirin \& clopidogrel $(60.00 \%){ }^{15}$ In the present study also aspirin and clopidogrel combination (46.90\%) was the most commonly prescribed antiplatelets because aspirin and clopidogrel combination is synergistic in preventing ischaemic episodes and reduces cardiovascular mortality, nonfatal MI and stroke. ${ }^{16}$

In the present study, Atorvastatin was the most commonly prescribed hypolipidemic drug (53.10). It decreases blood LDL cholesterol level effectively with increasing the HDL level. It also reduces the risk of coronary heart diseases, myocardial infarction and stroke effectively with fewer side effects. ${ }^{1}$

The present study found that commonly prescribed diuretic agent was furosemide $(20.35 \%)$ which was less as compared to previous studies, could be due to, they were prescribed to treat the patients with CCF and other reason could be in the government tertiary care hospital diuretics in combination with antihypertensives are not available.

The non cardiological drugs prescribed to treat associated medical conditions were antidiabetic drugs, antimicrobial agents, antiulcer agents, bronchodilators, anticonvulsants, corticosteroids and multivitamins as per the need.

In the present study, the average number of drugs per prescription was 6.53 which were in concordance with the previous study by Muhit MA, et al. ${ }^{1}$ The present and previous studies have not shown much variation in the average number of drugs per prescription.

\section{CONCLUSION}

The present study concludes, that most of the drugs were prescribed rationally according to the current treatment guidelines in indoor patients of cardiovascular diseases except the under use of ACEIs and ARBs in hypertensive diabetes mellitus patients. This can be changed by taking educative interventions to the physicians and by maintaining regular supply of these drugs in government tertiary care hospital. Despite the limitations, as it was a small sample size study conducted in a single centre, it was our sincere efforts to provide insight into the prescription pattern of indoor cardiovascular disease patients in a government tertiary care hospital. Further studies from time to time are required in drug prescription pattern and standard treatment guidelines 
should be circulated among practicing physicians to encourage rational prescription.

Funding: No funding sources

Conflict of interest: None declared

Ethical approval: The study was approved by the Institutional Ethics Committee

\section{REFERENCES}

1. Muhit MA, Rahman MO, Raihan SZ, Asaduzzaman M, Akbar MA, Sharmin N. Cardiovascular disease prevalence and prescription patterns at a tertiary level hospital in Bangladesh. Journal of Applied Pharmaceutical Science. 2012;2:80-4.

2. Gaziano TA, Gaziano JM. Epidemiology of Cardiovascular Disease. In Lango DL, Harrison's Principles of Internal Medicine, 18th edition. New york, Mc Graw Hill. 2012:1811-1816.

3. Shastry R, Bethi Y, Kumar JU. Trends in drug usage among elderly with cardiovascular diseases. Int J Basic Clin Pharmacol. 2014;3:723-5.

4. Shankar R, Partha P, Shenoy N. Prescribing patterns of drugs among patients admitted with cardiovascular disorders in the internal medicine ward: prescribing patterns in inpatients. Internet $\mathbf{J}$ Pharmacol. 2001;1(2).

5. Srishyla MV, Krishnamurthy M, Nagarani MA, Andrade C, Venkataraman BV. Prescription audit in an Indian Hospital setting using the DDD concept. Ind J Pharmacol. 1994;26:23-8.

6. Ramsay LE. Bridging the gap between clinical pharmacology and rational drug prescribing. $\mathrm{Br} \mathrm{J}$ Clin Pharmacol. 1993;35:575-6.

7. Vries MD, Heluling RH, Hogerzeil HV, Freste DA. Guide to good prescribing. A practical guide W.H.O. 1994.

8. Patil SB, Raikar SR, Patil S, Raikar DR. Prescription pattern of cardiovascular drugs in intensive cardiac care unit patients in a tertiary care hospital. Int $\mathrm{J}$ Basic Clin Pharmacol. 2015;4:1100-3.

9. Ghosh A, Bhagat M. Anthropometric and body composition characteristics in pre- and postmenopausal Asian Indian women: Santiniketan women study. Anthropol Anz. 2010;68:1-10.

10. Loscalzo J. Approach to the patient with possible cardiovascular Disease. In Lango DL, Harrison's Principles of Internal Medicine, 18th edition. New york, Mc Graw Hill. 2012:1817-20.

11. Zafar F, Ali H, Naveed S, Korai OU, Rizvi M. (2015) Drug Utilization Pattern in Cardiovascular Diseases: A Descriptive Study in Tertiary Care Settings in Pakistan. $J$ Bioequiv Availab. 2015;7:059-62.

12. Nagabushan H, Roopadevi HS, Prakash GM, Pankaja R. A prospective study of drug utilization pattern in cardiac intensive care unit at a tertiary care teaching hospital. Int $\mathrm{J}$ Basic Clin Pharmacol. 2015;4:579-83.

13. Christian RP, Rana DA, Malhotra SD, Patel VJ. Evaluation of rationality in prescribing, adherence to treatment guidelines, and direct cost of treatment in intensive cardiac care unit: a prospective observational study. Indian J Crit Care Med. 2014;18(5):278-84.

14. Datta S, Udupa AL. Antihypertensive drug use in patients having comorbid diabetes: Cross sectional prescription pattern study in a tertiary care hospital. Asian Journal of pharmaceutical and clinical research. 2010;3:43-5.

15. Tasneem S, Fouzia N. Drug utilization study in ischemic heart diseases associated with diabetes and hypertension. Int J Pharm Bio Sci. 2010;1(3):1-4.

16. Tripathi KD. Drug affecting coagulation, bleeding and thrombosis. In: Tripathi KD, editor. Text Book of Essentials of Medical Pharmacology. 7th Edition, New Delhi, Jaypee Brother Medical Publication. 2013:613-633.

Cit this article as: Rathod PS, Patil PT, Lohar RP, Patil AW. Prescription pattern in indoor patients of cardiovascular diseases: a descriptive study in a tertiary care hospital attached to a government medical college. Int J Basic Clin Pharmacol 2016;5:491-5. 